\title{
Importance of plant and bird traits on the seed removal pattern of endangered trees across different forest patches in southeast China
}

\author{
Ning Li $1^{*}$ (D), Shuai Zhang ${ }^{2}$ Y Yuan-Hao Ren ${ }^{1}$ and Zheng Wang ${ }^{2}$
}

\begin{abstract}
Seed removal by birds has been recognized as an important part of seed dispersal process in patchy forest areas; however, few studies have focused on the contribution of both plant and bird traits to seed removal. In this study, field data of seed removal for Taxus chinensis was combined with the data of bird and plant traits for analysis. The relevant traits of plants and birds that influenced $T$. chinensis-bird interaction were identified in a remnant patchy forest in yew ecological garden, Fujian Province, southeast China. Twenty bird species were found to forage and remove the seeds of $T$. chinensis. The number of bird species varied in different forest patches; however, their contribution to seed removal showed no significant differences. Both bird and plant traits were found to affect seed removal. The seed removal rate was positively affected by bird traits, such as foraging frequency and wing length, but decreased with body weight. The plant traits, such as number of fruits, tree height, canopy density, and crown width, which are related to safe shelter and food resource conditions, increased the seed removal rate. Our results underline the functional importance of bird and plant traits in the seed removal from endangered trees in patchy forests. Therefore, future conservation strategies should prioritize and recognize the role of both plant and bird traits in seed dispersal in remnant patchy forests.
\end{abstract}

Keywords: Seed removal, Bird trait, Plant trait, Hypsipetes leucocephalus, Patchy forest

\section{Introduction}

Habitat fragmentation is one of the most important factors responsible for the decline of biodiversity and disruption of ecological functions (Taubert et al. 2018; Liu et al. 2019; Peters et al. 2019). In remnant habitat patches, most of the ecological functions (pollination, seed dispersal) are not only disrupted by loss of species, but also affected by remnant patch size and quality (Bomfim et al. 2018; Emer et al. 2018). Small size and low quality of remnant habitat patches cannot accommodate the persistence of large-bodied species and

\footnotetext{
* Correspondence: lining196@126.com

${ }^{1}$ Institute of Applied Ecology, Nanjing Xiaozhuang University, Nanjing 211171, Jiangsu, China

Full list of author information is available at the end of the article
}

habitat specialist, thus disrupting seed dispersal service (Bregman et al. 2016; Donoso et al. 2016; Schupp et al. 2017).

Seed removal is an important aspect of seed dispersal; it is performed by different frugivorous bird species based on their functional traits (Farwig et al. 2017; Schupp et al. 2017). Both bird and plant traits could affect seed removal pattern in a fragmented habitat (Schupp et al. 2017). Morphological and behavioral traits of bird species could shape their role in seed removal pattern (Pérez-Méndez et al. 2015; Li et al. 2019). Largebodied species are generally recognized as keystone species owing to their huge requirement for food resources (Marjakangas et al. 2020). Most importantly, food selection by birds always affects the seed removal pattern of 
plant species. When birds treat fruits as their main food, the regeneration ability of plants in a patchy forest becomes similar to the one in a natural forest (Sasal and Morales 2013; Schupp et al. 2017). Plant traits also affect seed removal in fragmented remnant habitat (Dehling et al. 2016), for instance, large trees could be easily located by bird species, thus affecting bird foraging behavior (Cousens et al. 2015). A high number of available fruits attracts birds and affects their food selection ( $\mathrm{Li}$ et al. 2019). Although several studies on seed dispersal have already reported on such a trait approach for understanding the role of bird and plant traits in seed dispersal, the combined effects of plant and bird traits on the pattern of seed removal in fragmented remnant habitat patchy forests remain largely unknown.

Taxus chinensis (Pilger) Rehd. is an endemic gymnosperm in China; it is on the endangered species list and is legally protected in China. The wild population of $T$. chinensis regenerates poorly owing to low fecundity, high levels of seed predation, weak competitive ability of seedlings, and scarcity of microhabitats for recruitment. It is widely distributed in eastern China; however, most of the wild populations are patchily distributed, and their seeds are dispersed by avian frugivores (Li et al. 2019). In this study, we combined the field study of seed removal from T. chinensis with that of bird and plant traits and analyzed the results. With the analysis, we aim to identify the relevant traits of plants and birds that influence the seed removal pattern of $T$. chinensis in a remnant patchy forest.

\section{Materials and methods}

\section{Study site}

The study was conducted in a yew ecological garden (elevation $895-1218 \mathrm{~m}$ a.s.l., slope gradient $27^{\circ}$ ), located in the southern experimental area of the Meihua Mountain National Nature Reserve $\left(25^{\circ} 15^{\prime}-25^{\circ} 35^{\prime} \mathrm{N} ; 116^{\circ}\right.$ $45^{\prime}-116^{\circ} 57^{\prime}$ E) in the west part of Fujian Province, China. This site has the largest natural population of $T$. chinensis in China (approximately 490 adults, distributed in the evergreen broadleaf forest), including 200 trees that are older than 500 years. A national forest garden of 15 ha was established by the government in 2003 to protect these endangered trees; owing to their long-term human use, the vegetation around the forest garden is highly fragmented. The remnant evergreen broad-leaved forest patch interlaced with bamboo patches and mixed bamboo and broad-leaved patches to form a fragmented forest. The most important tree species in the remnant evergreen broad-leaved forest is T. chinensis (Fig. 1).

\section{Seed removal across different patches}

To compare seed removal across bamboo patch, mixed bamboo and broad-leaved patch, and evergreen broad- leaved forest patch, we quantified the frequency of bird visits to mature $T$. chinensis trees and number of foraged and removed seeds. Ten individuals were selected, with two individuals distributed in bamboo patch, four in mixed bamboo and broad-leaved patch, and four in evergreen broad-leaved forest patch. We observed the foraging behavior of birds from the opposite mountain slopes, at a distance of approximately $50 \mathrm{~m}$ using a telescope (Leica 70, Leica Microsystems GMBH, Mannheim, Germany). The birds that visited a mother tree were observed from landing to leaving. Observations lasted $8 \mathrm{~h}$ per day during the fruiting seasons of $T$. chinensis, from late October to early December, accounting for 58 days annually from 2018 to 2019 . We identified and counted the frugivorous bird species (Mackinnon et al. 2000), and recorded the number of seeds removed.

\section{Effects of bird and plant traits on seed removal across different patches}

We selected two behavioral traits (foraging frequency and foraging type, swallowing and pecking) and five morphological traits (bill length, body length, body weight, wing length, tail length, and tarsus length) to investigate the effects of bird traits on seed dispersal. Data on body weight were obtained by capturing 10 individuals of each species in the zoological garden of Nanjing and measuring their body weight using electronic scale. To obtain the other four morphological traits of the local bird species, we measured five males and five females of each bird species using the specimens preserved in the Museum of Nanjing Xiaozhuang University. We used the mean value of each trait for analyses. Furthermore, we compared five morphological traits of frugivorous bird species using ANOVA test after the data were log-transformed to approximate normality; size effects were removed in all cases using the residuals from the regressions on body length (snout-vent length, SVL). Five traits of each mature tree (tree girth, tree height, fruit amount, canopy density, and crown width) were also measured (Fang et al. 2009).

To determine the role of bird and plant traits in seed removal, we first compared mean foraging frequency and mean foraging amounts of each bird species. A seed dispersal interaction was built based on foraging frequency of birds. We also used ANOVA test to compare mean foraging frequency and mean foraging amounts among three forest patches. The number of seed removal events in the habitats was explained by the generalized liner mixed model (GLMM), where bird trait was a factor and study years and their interaction term the random factors. We used the glmer function in the lme4 $\mathrm{R}$ package Ver. 3.1.2 for the analysis. Since the number of seed removal events is a count data, the models were fitted with a Poisson distribution. We also tested the 


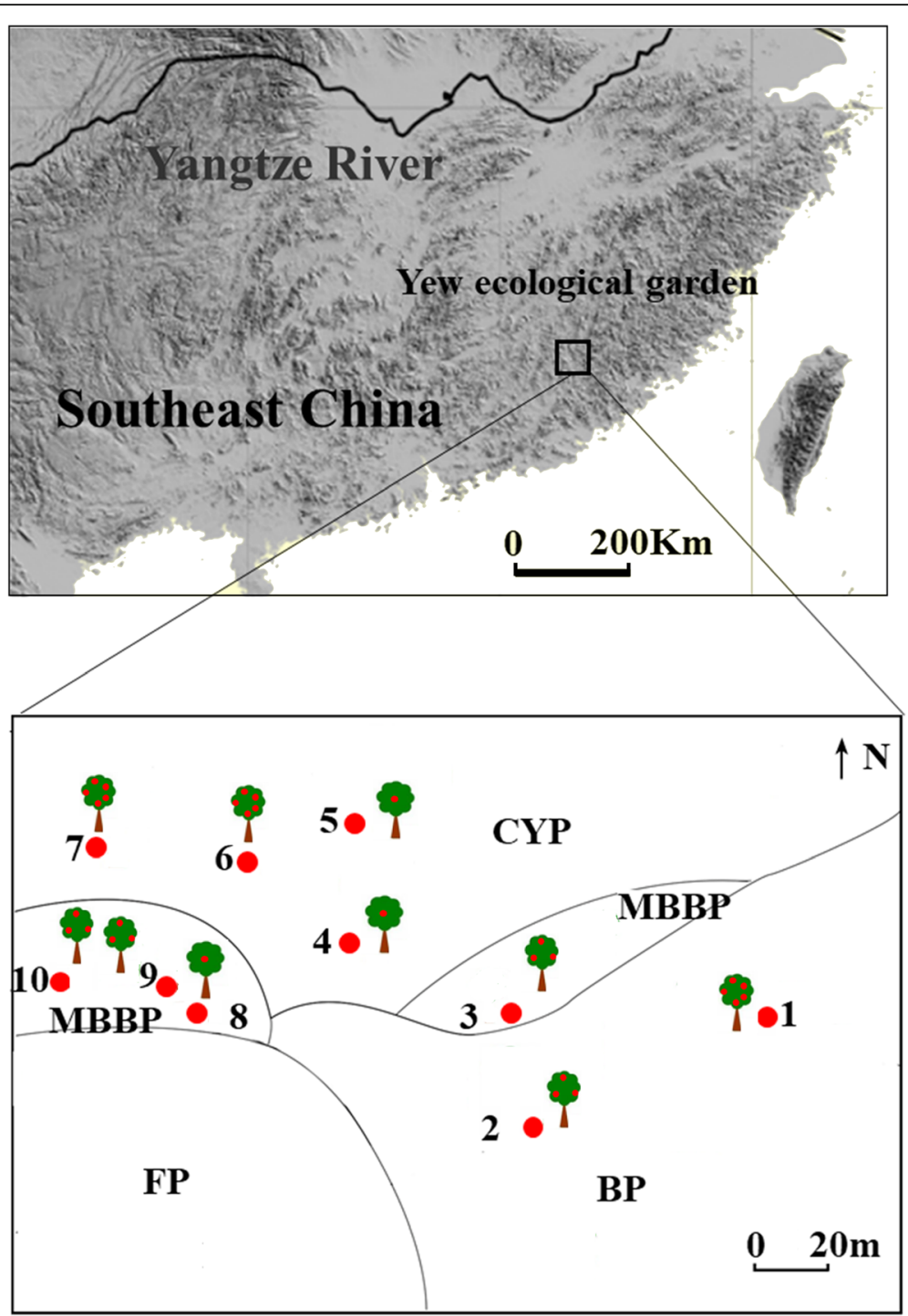

Fig. 1 Study site and distribution of mother trees in different patches in yew ecological garden, Fujian Province, southeast China. CYP: evergreen broad-leaved forest patch; MBBP: mixed bamboo and broad-leaved patch; BP: bamboo patch; FP: farmland patch. Red dots in the trees represent the fruit amount, 1 dot represent seeds $<$ 15,000; 3 dots represent 15,000 < seeds $<20,000 ; 5$ dots represent seeds $>20000$

effects of plant traits on seed removal, where plant trait was a factor and study years a random factor.

\section{Results}

During fruiting season, 20 bird species joined the seed removal interaction with $T$. chinensis. The number of bird species and their visiting frequencies showed annual changes during the 2 years, and 342 and 442 visits were recorded from 13 and 19 bird species that foraged on $T$. chinensis in 2018 and 2019, respectively. The main foraging bird species showed annual changes in the 2 years. Hypsipetes leucocephalus, Hemixos castanonotus, and Pycnonotus sinensis were the most important foraging species in 2018; they contributed $81.52 \%$ to the strength of the seed removal network. $H$. leucocephalus,
Chloropsis hardwickii, and Turdus obscurus were the most important foraging species in 2019; they contributed $77.38 \%$ to the strength of seed removal (Table 1, Fig. 2). In addition, 14, 18, and 10 species were recorded to forage the seeds in the bamboo patch, mixed bamboo and broad-leaved patch, and evergreen broad-leaved forest patch, respectively. Mean foraging frequency and mean foraging amounts of frugivorous birds showed no significant differences between the different types of forest patches $(p>0.05)$ (Table 2).

With regard to the effects of bird and plant traits on seed removal, our results revealed that five traits, namely, body length, body weight, wing length, tail length, bill length, and tarsus length $(p>0.05)$, did not differ in bamboo patch, mixed bamboo and broad-leaved 
Table 1 Frugivorous birds forage on the fruits of Taxus chinensis in the patchy habitat of yew ecological garden, Fujian Province, southeast China

\begin{tabular}{|c|c|c|c|c|}
\hline \multirow[t]{2}{*}{ Bird species } & \multicolumn{2}{|c|}{ Foraging frequency } & \multirow{2}{*}{$\begin{array}{l}\text { Mean } \\
\text { foraging } \\
\text { amount }\end{array}$} & \multirow{2}{*}{$\begin{array}{l}\text { Foraging } \\
\text { pattern }\end{array}$} \\
\hline & 2018 & 2019 & & \\
\hline Hypsipetes leucocephalus & 213 & 275 & $13.59 \pm 0.45$ & S \\
\hline Hemixos castanonotus & 37 & 20 & $10.53 \pm 0.86$ & S \\
\hline Pycnonotus sinensis & 30 & 24 & $9.20 \pm 0.77$ & S \\
\hline Urocissa erythrorhyncha & 9 & 5 & $12.14 \pm 2.91$ & S \\
\hline Spizixos semitorques & 5 & 7 & $11.83 \pm 1.86$ & S \\
\hline Chloropsis hardwickii & 3 & 35 & $8.87 \pm 1.01$ & S \\
\hline Dendrocitta formosae & 3 & 4 & $8.13 \pm 2.05$ & S \\
\hline Pycnonotus jocosus & 2 & 3 & $4.0 \pm 1.22$ & S \\
\hline Turdus obscurus & $\mathrm{nr}$ & 32 & $20.5 \pm 1.06$ & S \\
\hline Hypsipetes mcclellandii & $\mathrm{nr}$ & 5 & $9 \pm 1.97$ & S \\
\hline Garrulus glandarius & $\mathrm{nr}$ & 2 & $5.50 \pm 1.50$ & S \\
\hline Myophonus caeruleus & $\mathrm{nr}$ & 1 & 16 & S \\
\hline Garrulax monileger & $\mathrm{nr}$ & 1 & 5 & S \\
\hline Paradoxornis gularis & $\mathrm{nr}$ & 1 & 80 & S \\
\hline Pericrocotus solaris & 23 & 16 & $10.72 \pm 1.06$ & $P$ \\
\hline Yuhina castaniceps & 7 & 6 & $28.38 \pm 4.96$ & $P$ \\
\hline Pericrocotus flammeus & 2 & 3 & $4.25 \pm 1.11$ & $P$ \\
\hline Alcippe morrisonia & 4 & 1 & $11.80 \pm 5.26$ & $P$ \\
\hline Aegithalos concinnus & 4 & $\mathrm{nr}$ & $14.25 \pm 1.38$ & $P$ \\
\hline Yuhina zantholeuca & $\mathrm{nr}$ & 1 & 30 & $P$ \\
\hline Total & 342 & 442 & & \\
\hline
\end{tabular}

Data expressed as mean \pm SE; Foraging pattern: $S$ swallowing, $P$ pecking, $n r$ not record patch, and evergreen broad-leaved forest patch. GLMM results highlighted that the number of seed removal events was positively affected by the wing length, but negatively by the body weight (Table 3). In addition, our results showed that the effects of five traits-tree girth, tree height, fruit amount, canopy density, and crown width ( $p$ $>0.05$ ) - did not differ in bamboo patch, mixed bamboo and broad-leaved patch, and evergreen broad-leaved forest patch. Furthermore, GLMM results showed that tree height, fruit amount, canopy density, and crown width positively affected seed removal rate; however, the model showed that there was a negative relationship between tree girth and seed removal rate (Table 3).

\section{Discussion}

Our results demonstrated seed dispersal mutualism between 20 bird species and T. chinensis, built in the forest patches. The number of bird species in the different patches varied; however, their contribution to seed removal showed no significant difference. Our results also highlighted the significant role of bird and plant traits in the seed dispersal mutualism of $T$. chinensis in forest patches.

Our study demonstrated the role of bird traits, such as morphological and behavioral traits, in seed removal. As expected, number of seed removal events increased with bird foraging frequency, reflecting the role of bird foraging behavior on seed removal. Food selection by birds influences the seed removal pattern of plant species in which seeds serve as the main food for the birds (Sasal and Morales 2013; Farwig et al. 2017; Schupp et al. 2017). However, our results also showed that large birds did not play a critical role in seed removal because seed removal decreased with

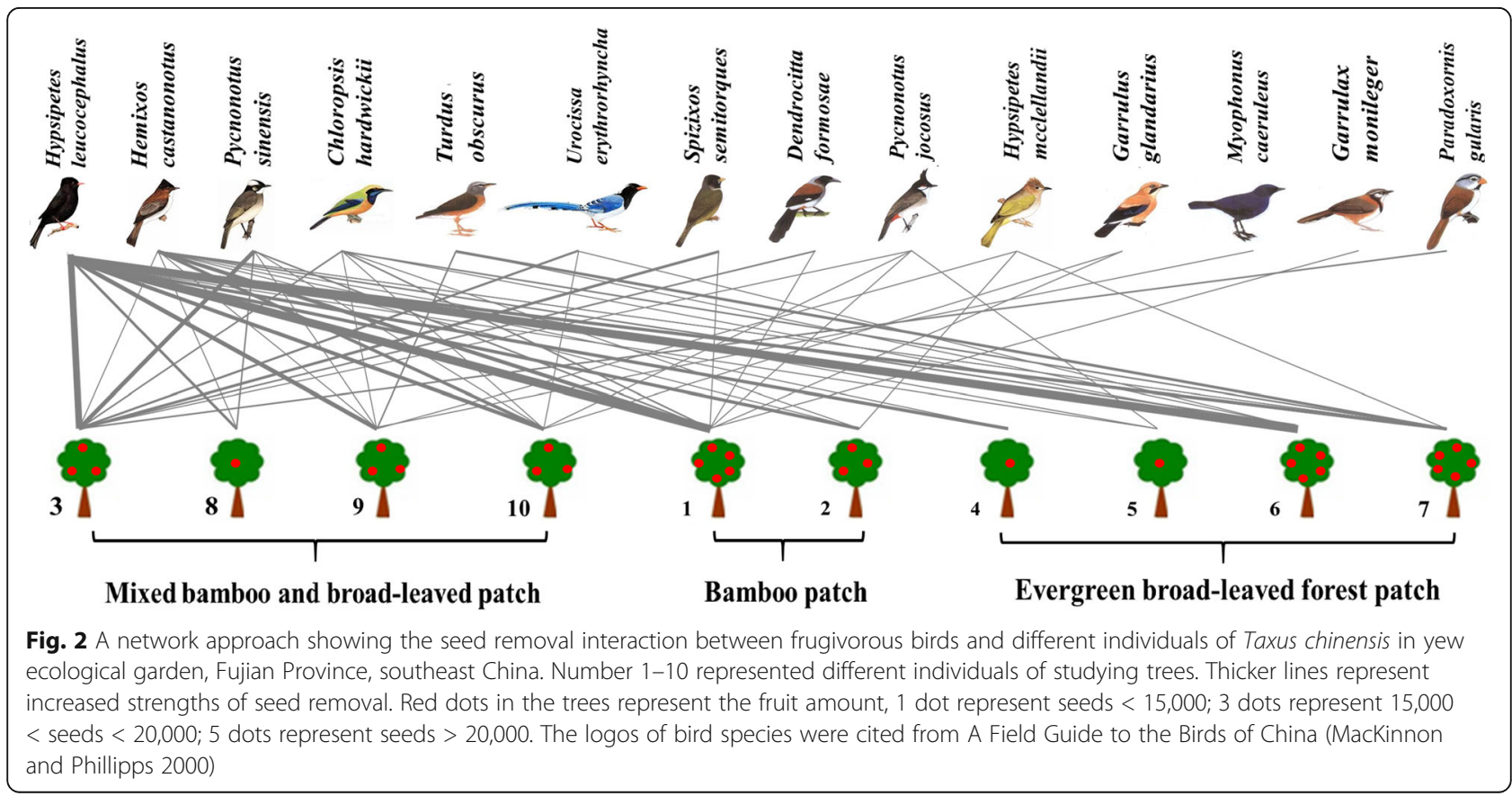


Table 2 Comparison of bird species and their foraging behaviors on each individual of Taxus chinensis across different habitat patches in the patchy habitat of yew ecological garden, Fujian Province, southeast China

\begin{tabular}{llllll}
\hline Patch type & Bamboo patch & Mixed bamboo and broad-leaved patch & Evergreen broad-leaved forest patch & $F$ & $p$ \\
\hline Number of bird species & 14 & 18 & 10 & $\mathrm{nr}$ & $\mathrm{nr}$ \\
Mean foraging frequency & $62.50 \pm 2.50$ & $41.13 \pm 6.13$ & $38.67 \pm 10.33$ & 3.424 & 0.168 \\
Mean foraging amounts & $709.50 \pm 21.50$ & $446.87 \pm 52.88$ & $645.17 \pm 125.83$ & 2.944 & 0.196 \\
\hline
\end{tabular}

$n r$ not record

large body weight of the birds. The interaction between small-bodied bird species (H. leucocephalus, H. castanonotus, $P$. sinensis) and plants could enhance plant recruitment in patchy forests because large-bodied bird species are more threatened globally and have a higher risk of extinction than small-bodied bird species (Gaston and Blackburn 1995; Bregman et al. 2016). Therefore, it is important that $T$. chinensis seeds are dispersed by small-bodied bird species, as it would enhance their chances of persistence in patchy forests.

Furthermore, our results revealed that the number of seed removal events increased with plant traits, such as the number of fruits, tree height, canopy density, and

Table 3 Coefficients of generalised linear mixed-effects models with a Poisson distribution testing the effects of the factors of bird and plant traits on seed removal patterns of Taxus chinensis in the patchy forest of yew ecological garden, Fujian Province, southeast China

\begin{tabular}{|c|c|c|c|c|}
\hline Parameter & Estimate & SE & Z & $p$ \\
\hline \multicolumn{5}{|c|}{ Effects of bird traits on seed removal } \\
\hline Intercept & 2.090 & 0.192 & 10.887 & $<2 \mathrm{E}-16^{* * *}$ \\
\hline Body weight & -0.011 & 0.001 & -7.896 & $2.88 \mathrm{E}-15^{* * *}$ \\
\hline Body length & -0.004 & 0.007 & -0.635 & 0.525 \\
\hline Tail length & -0.002 & 0.006 & -0.411 & 0.681 \\
\hline Wing length & 0.030 & 0.005 & 5.996 & $2.02 \mathrm{E}-09^{* * *}$ \\
\hline Bill length & 0.010 & 0.014 & 0.752 & 0.452 \\
\hline Foraging frequency & 0.046 & 0.001 & 74.519 & $<2 \mathrm{E}-16^{* * *}$ \\
\hline \multicolumn{5}{|l|}{ Random effects } \\
\hline Groups & Variance & Std. Dev. & & \\
\hline Years & 7.67E-05 & 0.009 & & \\
\hline \multicolumn{5}{|c|}{ Effects of plant traits on seed removal } \\
\hline Intercept & -0.204 & 0.168 & -1.217 & 0.224 \\
\hline Tree girth & -0.938 & 0.068 & -13.815 & $2 \mathrm{E}-16^{* * *}$ \\
\hline Tree height & 0.064 & 0.006 & 10.313 & $2 E-16^{* * *}$ \\
\hline Fruit amount & 0.269 & 0.038 & 7.133 & $9.79 \mathrm{E}-13^{* * *}$ \\
\hline Canopy density & 5.429 & 0.284 & 19.094 & $2 \mathrm{E}-16^{* * *}$ \\
\hline Crown width & 0.050 & 0.005 & 11.089 & $2 \mathrm{E}-16^{* * *}$ \\
\hline \multicolumn{5}{|l|}{ Random effects } \\
\hline Groups & Variance & Std. Dev. & & \\
\hline Years & 0.005 & 0.074 & & \\
\hline
\end{tabular}

crown width, that are related to safe shelter and food resource conditions. Food condition could affect bird foraging behavior in patchy forests (Sasal and Morales 2013; Schupp et al. 2017). In our study, the number of seed removal events increased with the number of fruits. A high number of available fruits could shape food selection by birds owing to good attraction effect, which was also supported by other studies (Dehling et al. 2016; Li et al. 2019). In addition, plants with safe condition also affect feeding behavior of frugivorous birds, thus affecting seed removal (Cody 1985). In our study, the number of seed removal events increased with tree height, canopy density, and crown width. Tall trees with large canopy density provided safe shelter for escaping predators resulting in a higher foraging visitation of birds (Cody 1985; Sasal and Morales 2013; Cousens et al. 2015).

\section{Conclusion}

Our results successfully developed a trait-based analysis of species interactions to identify the functional bird and plant traits that affected seed removal pattern. Our results also underlined the functional importance of bird behavioral traits in the seed removal from endangered trees in patchy forests. Plant traits related to safe shelter and food resource conditions affected bird foraging behavior, thus affecting plant seed removal. However, our study reflected only an indirect contribution of bird and plant traits to seed removal in patchy forests, owing to small sample size of the study. Researchers need to understand and consider in future research studies the relationship between the background conditions of bird and plant traits and seed removal for a whole plant community in different forest patches.

\section{Acknowledgements \\ We thank two anonymous reviewers for their valuable comments.}

\section{Authors' contributions}

N.L. and Z.W. designed the study. N. L. selected the study site and organized field work. N.L. managed project administration and led the manuscript writing, with contributions from all the authors. The authors read and approved the final manuscript.

Funding

This research was funded by National Natural Science Foundation of China, grant number 31700468, and the Natural Science Foundation of Jiangsu Province, grant number BK2017636. 
Availability of data and materials

Not applicable.

Ethics approval and consent to participate

Not applicable.

\section{Consent for publication}

Not applicable.

\section{Competing interests}

The authors declare that they have no competing interests.

\section{Author details}

'Institute of Applied Ecology, Nanjing Xiaozhuang University, Nanjing 211171, Jiangsu, China. ${ }^{2}$ College of Biology and Environmental Science, Nanjing Forestry University, Nanjing 210037, China.

Received: 8 June 2020 Accepted: 13 August 2020

Published online: 26 August 2020

\section{References}

Bomfim JA, Guimarães PR, Peres CA et al (2018) Local extinctions of obligate frugivores and patch size reduction disrupt the structure of seed dispersal networks. Ecography 41:1899-1909

Bregman TP, Lees AC, MacGregor HEA et al (2016) Using avian functional traits to assess the impact of land-cover change on ecosystem processes linked to resilience in tropical forests. Proc R Soc B-Biol Sci 283:20161289

Cody ML (1985) Habitats Selection in Birds. Academic Press, London

Cousens RD, Hill J, French K et al (2015) Towards better prediction of seed dispersal by animals. Funct Ecol 24:1163-1170

Dehling DM, Jordano P, Schaefer HM et al (2016) Morphology predicts species' functional roles and their degree of specialization in plant-frugivore interactions. Proc R Soc B-Biol Sci 283:20152444

Donoso I, García D, Rodríguez-Pérez J et al (2016) Incorporating seed fate into plant-frugivore networks increases interaction diversity across plant regeneration stages. Oikos 125:1762-1771

Emer C, Galetti M, Pizo MA et al (2018) Seed-dispersal interactions in fragmented landscapes - a metanetwork approach. Ecol Lett 21:484-493

Fang JY, Wang XP, Shen ZH et al (2009) Methods and protocols for plant community inventory. Biodiver Sci 17:533-548

Farwig N, Schabo DG, Albrecht J (2017) Trait-associated loss of frugivores in fragmented forest does not affect seed removal rates. J Ecol 105:20-28

Gaston KJ, Blackburn TM (1995) Birds, body size and the threat of extinction. Philos Trans R Soc B-Biol Sci 347:205-212

Li N, Wang Z, Zhang S, Yan C, Li XH, Lu CH (2019) Importance of bird traits for seed dispersal patterns of co-fruiting trees in a patchy forest. Integr Zool 14 : $470-478$

Liu JJ, Coomes DA, Gibson L et al (2019) Forest fragmentation in China and its effect on biodiversity. Biol Rev 94:1636-1657

MacKinnon J, Phillipps K (2000) A Field Guide to the Birds of China. Oxford University Press, New York

Marjakangas EL, Abrego N, Grøtan V et al (2020) Fragmented tropical forests lose mutualistic plant-animal interactions. Diver Distrib 20:154-168

Pérez-Méndez N, Jordano P, Valido A (2015) Downsized mutualisms: consequences of seed dispersers' body-size reduction for early plant recruitment. Perspect Plant Ecol 17:151-159

Peters MK, Hemp A, Appelhans T et al (2019) Climate-land-use interactions shape tropical mountain biodiversity and ecosystem functions. Nature 568:88-92

Sasal Y, Morales JM (2013) Linking frugivore behavior to plant population dynamics. Oikos 122:95-103

Schupp EW, Jordano P, Gómez JM (2017) A general framework for effectiveness concepts in plant-animal mutualisms. Ecol Lett 20:577-590

Taubert F, Fischer R, Groeneveld J et al (2018) Global patterns of tropical forest fragmentation. Nature 554:519-522

\section{Publisher's Note}

Springer Nature remains neutral with regard to jurisdictional claims in published maps and institutional affiliations.

\section{Submit your manuscript to a SpringerOpen ${ }^{\circ}$ journal and benefit from:}

- Convenient online submission

- Rigorous peer review

- Open access: articles freely available online

- High visibility within the field

- Retaining the copyright to your article

Submit your next manuscript at $\boldsymbol{\nabla}$ springeropen.com 